Conclusion ACP has benefits in improving decision making. More needs to be done to improve implementation of ACP for patients with heart failure.

\section{OP70 NORMATIVE PRINCIPLES OF ADVANCE CARE PLANNING: A SYSTEMATIC LITERATURE REVIEW}

${ }^{1} \mathrm{~N}$ Fleuren*, ${ }^{1} \mathrm{M}$ Depla, ${ }^{2} \mathrm{D}$ Janssen, ${ }^{1} \mathrm{M}$ Huisman, ${ }^{1} \mathrm{C}$ Hertogh. ${ }^{1}$ Amsterdam UMC, Vrije Universiteit Amsterdam, Amsterdam Public Health, Amsterdam, Netherlands: ${ }^{2} \mathrm{MUMC}+$ Maastricht, Netherlands

\subsection{6/spcare-2019-ACPICONGRESSABS.70}

Background Since the introduction of the concept of advance care planning (ACP), many studies have been conducted exploring beneficial effects. These studies show a heterogeneity in clinical endpoints, which reflects diversity of goals connected to ACP. Clarification of underlying normative principles of ACP is crucial in understanding both motivation and hesitation to initiate ACP among health care professionals and patients. This study aims to clarify normative principles of ACP and to get insight in the range of normative principles that comprise the legitimacy of ACP.

Methods Systematic literature search in PubMed, EMBASE, PsychInfo, CINAHL and Cochrane Library, using various search terms for 'ACP' and 'ethics'. Articles on normative aspects of ACP were included, based on title and abstract. Due to the quantity of inclusions, of which many had similar content, purposive sampling was used to select articles for full text document analysis. Analysis stopped once saturation was reached. Sensitivity analysis was performed to guarantee that unfrequently mentioned goals and objections were found as well.

Results In total, 6497 unique articles were found of which 183 were included. Saturation was reached after document analysis of 55 articles (30\%); this yielded 211 codes concerning normative principles of ACP. We identified 5 main normative principles for ACP: respecting individual patient autonomy, improving quality of care, strengthening relationships, improving quality of life, and reducing overtreatment. Conclusion Defining normative principles of ACP should serve as a starting point when developing ACP interventions and selecting outcome measures to evaluate ACP interventions.

\section{OP71 ACP ALBERTA: COLLABORATIVE ACTION OF HEALTH CARE, LEGAL, GOVERNMENT, COMMUNITY AND ACADEMIC SECTORS TO INCREASE PARTICIPATION IN ADVANCE CARE PLANNING}

${ }^{1} \mathrm{M}$ Douglas*, ${ }^{2} \mathrm{~K}$ Fassbender, ${ }^{3} \mathrm{~N}$ Ries, ${ }^{4} \mathrm{E}$ Wasylenko, ${ }^{5} \mathrm{P}$ Biondo, ${ }^{5} \mathrm{~J}$ Simon, ${ }^{5} \mathrm{~N}$ Hagen, ${ }^{6}$ BS Chamaschuk. ' University of Alberta, Edmonton, Canada; ${ }^{3}$ University of Technology Sydney, Sydney, Australia; ${ }^{4}$ Health Quality Council of Alberta, Calgary, Canada; ${ }^{5}$ University of Calgary, Calgary, Canada; ${ }^{6}$ Reynolds Mirth Richards and Farmer, Edmonton, Canada

\subsection{6/spcare-2019-ACPICONGRESSABS.71}

Background In 2014, Alberta's health service providers implemented a province-wide Advance Care Planning (ACP) and Goals of Care Designation policy. Despite significant efforts, barriers to full implementation remain including lack of public comprehension across health, legal and other public systems. A World Café consultation revealed multi jurisdictional recommendations to 'normalize ACP.'
Methods Through the ACP Collaborative Research Innovation Opportunities program, we formed a collaboration with lawyers, Legal Education Society of Alberta, Canadian Bar Association, Law Society of Alberta, palliative care physicians, patient advocates, academics, provincial health care providers and other stakeholders. A community of practice propagated spontaneously. Surveys and focus groups identified barriers, knowledge and resource gaps, and novel solutions, including joint health-legal education.

Results Traditional approaches to ACP have been siloed. We expand on the innovative medico-legal framework to include other stakeholders including community agencies, faith groups, health advocacy agencies, national ACP projects, and the financial planning and insurance industries. Ongoing collaborative activities include community engagement, education, policy and practice innovation, which bundles activities relating to health care planning with those relating to personal and financial planning. Our business case addresses the identified gaps and adopts public recommendations through activities to coordinate, integrate and/or support development/implementation of a community volunteer program, an electronic registry for ACP and Goals of Care documentation, and a legal toolkit.

Conclusion In practice, ACP spans medical, legal, social and personal domains. Multi-disciplinary and multi-sector approaches are posited to improve knowledge and uptake of ACP while improving the quality of life of Albertans.

\section{OP72 WHO IS IN CONTROL? CULTURAL AND INSTITUTIONAL BARRIERS TO EOL DECISION IN JAPAN AND THE UNITED STATES}

A Morita*. Hospice Hawaii, Honolulu, USA

\subsection{6/spcare-2019-ACPICONGRESSABS.72}

Japanese and American healthcare providers enjoy abundant medical resources at their disposal, yet both systems often fail to adequately address a patient's end-of-life (EOL) wishes for vastly different reasons.

In a society as highly structured in hierarchical and patriarchal dimensions as Japan's, a terminal patient's wishes are often superseded by the treating physician's suggestions in deference to the doctor's education and social status. In addition, a family member who has cultural authority tends to speak and make decisions on behalf of the dying person and the family.

Similarly, American healthcare providers often avoid the topic of EOL decision-making to deflect away from the realization that in spite of their formidable arsenal of available medical treatments, they are powerless to help. The American system of medical training also encourages physicians to advise their patients to fight an incurable disease to the end because the hope of prolonging life is never lost.

These cultural versus institutional factors have the same result. Oftentimes, the EOL wishes of a terminal patient is either not heard or lost at best. In either case, these factors have a major detrimental impact on the quality of a patient's end-of-life experience as their wishes fall prey to more dominant cultural or social factors. This theoretical study discusses the importance of EOL conversation in providing quality care, and discusses how the medical professions in both countries 
can approach EOL discussions with the cultural sensitivity and understanding to improve the quality of living and dying.

\section{OP73 DIFFERENCES BETWEEN ADVANCE DIRECTIVES AND ADVANCE CARE PLANNING IN THE ITALIAN LAW 219/2017}

${ }^{1} \mathrm{~F}$ Ingravallo*, ${ }^{2} \mathrm{~L}$ De Panfilis. ${ }^{1}$ University of Bologna, Bologna, Italy; ${ }^{2}$ Azienda USL-IRCCS di Reggio Emilia, Reggio Emilia, Italy

10.1136/spcare-2019-ACPICONGRESSABS.73

Background The Law 219/2017, entered into force on January 31, 2018, regulated for the first time advance directives (ADs) and advance care planning (ACP) in Italy. We aimed to examine main legal differences between $\mathrm{ADs}$ and $\mathrm{ACP}$ according to this law.

Methods The Law 2019/2017 was analyzed, and relevant differences between ADs and ACP were described.

Results ADs and ACP differed mainly with regard to subjects involved, legal formalities required, and the healthcare professionals' duty to respect the patient's will. ADs may be made by mentally competent adults through notarization or delivery to a municipal office or to a health facility with electronic health record database structure; ADs are, in principle, binding for physicians, but the physician, in agreement with the healthcare proxy, may go against the patient's will in some circumstances. On the other hand, ACP may be carried out by the patient and the physician with regard to the expected trajectory of a chronic disabling disease or a progressive illness with a poor prognosis; there are no particular legal formalities for establishing the ACP, which should be included in the patient record; ACP is always binding for both the physician and the healthcare staff members.

Conclusion(s) The Italian Law 219/2017 set up a binary approach to guaranteeing patient self-determination in the case of lack of decision-making capacity, establishing the primacy of the ACP carried out with the physician when patients' outcomes are already predictable.

\section{OP74 ADVANCE CARE PLANNING BY PROXY: AN ANALYSIS OF THE ETHICO-LEGAL FOUNDATION}

RJ Jox*. Lausanne University Hospital, Lausanne, Switzerland

\subsection{6/spcare-2019-ACPICONGRESSABS.74}

Background Advance care planning (ACP) in practice often includes conversations with family caregivers of those patientes who have already lost decision-making capacity. This approach has been defined as ACP by proxy and rightly been pointed out as a distict activity, but it blatantly lacks an ethico-legal foundation.

Method Theoretical analysis, drawing from bioethics, philosophical ethics, and international medical law.

Results In contrast to ACP by the patient, ACP by proxy has its core roots not on direct, but indirect patient autonomy. While the patient with his or her autonomous preferences is also at the heart of the process, the epistemological approach to assess these preferences has to pass via surrogates and others close to the patient. As the patient commonly cannot participate in the conversation, his or her preferences cannot be jointly developed by a kind of maieutic process, but have to be approximated by substituted judgment. Another key difference is the ethico-legal responsibility placed on the surrogate decision maker as well as on the health care team and ACP facilitator linked to this substituted judgment.

Conclusion Irrespective of shared values, ACP by the patient and ACP by proxy have distinct ethico-legal features that warrant particular consideration in the practical process of ACP, the qualification of ACP facilitators, and the documents used.

\section{OP75 THE DECISION MAKING CAPACITY IN AMYOTROPHIC LATERAL SCLEROSIS (ALS)}

${ }^{1} \mathrm{M}$ Marogna*, ${ }^{2} \mathrm{~N}$ Balletto. 'Villa Scassi Hospital, ASL3 Genovese, Genoa, Italy; ${ }^{2}$ Gigi Ghirotti Association, Genoa, Italy

\subsection{6/spcare-2019-ACPICONGRESSABS.75}

Background From the beginning and during the disease the ALS patients have to take difficult decisions about care and end of life. A sensible and open communication among patient and clinicians is an indispensable tool to ensure the freedom of choice and the recognition of the responsibility for everyone. Any intervention by the health professionals cannot forget the clinical complexity and the subjectivity of the patients who exercises their rights to know and to choose among technology opportunities. The aim of the study is to identify those elements that influence the patient's choices.

Methods We examined 200 ALS patients taking care by palliative multidisciplinary team for 18 months about: withholding and withdrawing vital supports, mobility and communication aids, rehabilitation care and dying setting. We registered the respect for advance directives, the changing's patients minds, the making informed choices, the clinicians attitudes about care planning and communication disability.

Results For every choice the decision making involves scientific aspects, patient's quality of life, and community resources too. We showed that the choices are often not real free but depending on the clinicians' point of view, the availability of high technology aids and the clinician-patient communication skills.

Conclusion The negotiation is the new aspect of the physician-patient relationship founded on empathy, respect and recognition of different competences. The clinician' ethicalclinical reasoning could be a useful tool to improve the patient ability to choose on difficult clinical situations.

\section{OP76 ADVANCE CARE PLANNING: CORE COMPETENCY OF ELDERLY CARE MEDICINE IN THE NETHERLANDS}

${ }^{1} \mathrm{D}$ Janssen, ${ }^{2} \mathrm{C}$ Hertogh* ${ }^{2} \mathrm{CIRO}$, Horn, Netherlands; ${ }^{2}$ VUmc, Amsterdam, Netherlands

\subsection{6/spcare-2019-ACPICONGRESSABS.76}

Target audience professional caregivers, including physicians, nurses and allied healthcare professionals, researchers, policy makers.

Description The Dutch elderly care physician is a physician who specializes in long-term care for frail elderly people and patients with complex chronic health problems. Advance care planning (ACP) is a corner stone of elderly care medicine. The current session shows the importance of 